\title{
Provider perspectives on barriers to family planning quality in Uganda: a qualitative study
}

\author{
John Frank Mugisha, Heidi Reynolds
}

\begin{abstract}
Background and methodology Provider perspectives on the quality of family planning services have been overlooked in quality of care research and interventions. This qualitative study was carried out in four districts in Uganda, a country where lack of access to quality family planning services remains a challenge. Using four focus group discussions, 16 provider in-depth interviews and nine manager in-depth interviews, this study documented providers' perceptions of quality of care and of barriers to quality services at the organisational and societal levels. To guide study development, analysis and interpretation, the authors relied on an ecological framework where providers' abilities are shaped by the larger organisational and societal environments in which providers live and work.
\end{abstract}

Results Providers felt that organisational factors, such as supply availability, workload and their own knowledge and skills, affected their abilities to offer quality care. At the same time, providers were challenged by societal factors such as male partner participation, financial constraints, misconceptions and leadership support. While making changes to the elements of quality care that clients experience is important, it is not sufficient in view of the organisational and social barriers.

Discussion and conclusions Across the different levels of the ecological framework, providers face barriers to providing quality family planning services that are synergistic. Solutions to improve quality of care must address also limitations at the organisational and societal levels since efforts to overcome a particular constraint are less likely to be successful if this interdependence is not taken into account.

Keywords family planning, health care provider, quality, Uganda

J Fam Plann Reprod Health Care 2008; 34(1): 37-41

(Accepted 7 March 2007)

\section{Background}

More than a decade ago, the International Conference on Population and Development Program of Action acknowledged that quality family planning services are related to the level and continuity of contraceptive use. ${ }^{1}$ Evidence exists of a positive relationship between quality of family planning, acceptance of contraceptive methods, and method continuation, ${ }^{2-5}$ despite difficulties establishing an empirical link between programmes designed to improve quality of care and contraceptive use. 3,6

The potential to increase contraceptive use and continuation using an approach that is responsive and respectful to clients makes increasing the quality of care in family planning programmes a goal in and of itself. In Uganda, lack of access to quality family planning services remains a challenge, ${ }^{7}$ and fertility rates have remained high particularly in rural areas (i.e. 7.4 births per woman compared to 4 in urban areas) despite declines experienced by Uganda's neighbours. ${ }^{8}$ The current level of modern contraceptive use by all women is relatively low at $16.5 \%$, while unmet need for contraception ranges from $23.4 \%$ in rural areas to $36.2 \%$ in urban areas. ${ }^{9}$ Only a limited method mix (i.e. male condoms, pills and injectables) is available in most clinics ${ }^{10}$ and discontinuation is a problem. ${ }^{11}$

In striving to provide quality care, programmes have centred on client perspectives and on services that meet clients' needs. ${ }^{12}$ Providers are often pointed to as targets

\section{Regional Centre for Quality of Health Care, Makerere University Institute of Public Health, Kampala, Uganda John Frank Mugisha, BA, MA, Research Fellow}

Family Health International, Research Triangle Park, NC, USA Heidi W Reynolds, PhD, MPH, Health Services Research Scientist

Correspondence to: Mr John Frank Mugisha, Regional Centre for Quality of Health Care, Makerere University School of Public Health, PO Box 29140, Kampala, Uganda.

E-mail: fmugisha@rcqhc.org

\section{Key message points}

- Some barriers to improving family planning quality are outside providers' control but influence the quality of care they are able to provide.

- Interventions need to address barriers at the organisational (e.g. inadequate training opportunities) and societal levels (e.g. clandestine method use) if they are to improve family planning quality.

for intervention since their knowledge, skills, attitudes and opinions directly influence the quality of services clients receive. ${ }^{13,14}$ However, programmes acknowledge that providers' ability to provide quality care is nested in the organisational and social milieus in which they work. Thus, some programmes are adopting techniques that improve health care quality by focusing on the systems in which providers work. 15,16

Ironically, despite their central role in service delivery and programme improvement, provider perspectives on quality of care have often been overlooked. ${ }^{13}$ What there is suggests that organisational factors, such as supplies and equipment and infrastructure, severely constrain their ability to offer quality services. ${ }^{17,18}$ Furthermore, principal factors associated with unmet need for contraception are societal in nature (e.g. familial disapproval). ${ }^{19}$ We lack an understanding from the provider perspective about how the larger social and community milieu influences providers' ability to provide quality care.

In an ecological framework, providers' abilities are shaped not only by personal attitudes, beliefs and values but also by the organisation in which they work and by forces in the larger social milieu. ${ }^{20}$ Ecological models lead to interventions that seek to make changes not only at the interpersonal level but also at the societal, policy and physical environments. ${ }^{21}$ Insight into the problems and solutions associated with quality family planning services can be gained by understanding the providers' perspective about organisational and social factors that influence their ability to provide quality care. Thus, this study's objective 
was to document family planning provider perceptions of quality of care and of barriers to providing quality services at the organisational and societal levels in Uganda.

\section{Methods}

This study was conducted from June to August 2002 in four districts of Uganda: Bushenyi (western region), Iganga (eastern), Lira (northern) and Mpigi (central). The districts were selected because they represented each of the four regions of Uganda, had relatively well-established health systems, and were not part of the internal conflict between the government and the Lord's Resistance Army. Also excluded were 12 districts covered under the US Agency for International Development (USAID)-funded Delivery of Integrated Services for Health (DISH) Project, which sought to improve the quality of reproductive health services, to avoid problems with interpreting how this project may have influenced provider responses.

The four districts are $95 \%$ rural and the large majority of the population depends on subsistence agriculture. The districts have high fertility rates coupled with contraceptive prevalence rates (CPR) between $8 \%$ (Bushenyi) and 15\% (Mpigi) (Dr Katureebe, District Director of Health Services (DDHS), Bushenyi, personal communication, 17 November 2005; Dr Nasanga, DDHS, Mpigi, personal communication, 29 November 2005). These rates are below the national CPR of $16.5 \%$.

Data were collected using focus group discussions (FGDs) and in-depth interviews with family planning providers from government health clinics and in-depth interviews with family planning managers. A purposive sample approach was used. For FGDs, female midwives with at least 1 year of experience providing family planning services and who were willing to participate were recruited. In the event that a midwife was not available, a nurse was eligible.

Participants for the in-depth interviews were selected after each FGD session ended. The facilitator and notetaker independently selected the names based on the following criteria: individuals were forthcoming during FGDs, they expressed diverse viewpoints and they were available to be interviewed 2 weeks later.

In-depth interviews were also conducted with family planning managers to capture the viewpoints of those who indirectly affect the quality of care through supervision, policy and management. Managers are technically responsible for developing health plans, budgeting and supervising the provision of health services, including family planning.

Data collection instruments were semi-structured and open-ended. Specifically, the areas covered during the 60to 90 -minute FGDs and in-depth interviews with providers were:

- definitions of quality of care

- perceptions of service quality

- attitudes and beliefs about methods

- perceptions of clients

- adequacy of supplies and equipment

- experience with various methods

- motivation

- work environment

- job satisfaction.

Manager interviews also focused on the definitions of quality of care, but they were in a position to address policy, guidelines and other mechanisms that influence family planning quality and their perceived barriers to provision of high-quality family planning.

Interviews were conducted in English and all were audiotaped and transcribed. Data were analysed for content, and themes and patterns were identified and organised using CDC EZ-Text (v.3.06). ${ }^{22}$ Two coders (one being the first author) developed and applied codes. Question topics and cross-cutting themes raised by respondents informed code development. The second author monitored the coding process to ensure that there was consistency in the coding system. Analysis and interpretation were done independently by the two authors. They identified major themes by grouping together similar quality of care factor codes. These themes were organised into societal or organisational factors affecting quality of care.

\section{Ethical approval}

This study received ethical approval from committees at Family Health International in the USA and in Uganda at the National Council for Science and Technology. All participants provided oral consent to be interviewed and consent was documented on audiotape.

\section{Results}

Four FGDs were conducted with 38 female providers with a range of participants per group from seven in Mpigi to 11 in Lira. Most participants were enrolled midwives; six were nurses. Nearly half of all providers lacked formal training in family planning and were trained on the job. Almost half of the providers were aged between 31 and 45 years and one-quarter were aged between 46 and 50 years. Most providers were married, although six were single and 10 were separated, divorced or widowed. No major differences in these characteristics were observed among providers across the four districts.

Sixteen providers participated in the in-depth provider interviews (four from each FGD). They had spent an average of 5.4 years providing family planning services at their clinics; almost half were in charge of the family planning clinic or maternity care department.

Of the nine managers who participated, five were female and four were male. Three were district nursing officers, four were medical officers in charge of health subdistricts, one was a district reproductive health focal person and one was the DDHS. The mean length of time the managers had served in their current designations was 3.7 years.

\section{Organisational factors}

Availability of methods and supplies, workloads and lack of provider knowledge and skills were identified as key organisational factors influencing quality of care.

In FGDs, lack of supplies was the most commonly cited barrier to quality family planning services. The few providers who reported that they had enough contraceptive supplies still said they lacked disinfectant, gloves, family planning cards and educational materials. Some stock-outs of contraceptives and other supplies were reported to last 3-6 months and led to discontinuation.

"We had no Depo-Provera, for a long time ... over 6 months actually. [Question: So what were you doing by that time?] Those who wanted Depo were not being served because most people here do not like oral contraceptives." (Manager)

Providers felt lack of supplies led to longer client waiting times, unwanted pregnancies, rendered providers unable to treat or diagnose sexually transmitted infections (STIs) (which then meant women erroneously attributed STI symptoms to contraceptive side effects) and could expose clients to infections because of improper sterilisation of equipment. 
"Clients tend to wait for a long time because you carry out a procedure and then you wait for the same instrument to be sterilised and then carry out another procedure." (Iganga, in-depth interview)

Providers and managers suggested ways of improving the system. They both suggested that advance planning and ordering would help because stocks were often left to run low or out before more supplies were ordered, but that supervisors should intensify their monitoring to ensure that all clinics made timely requests for supplies.

"... to ensure quality service given there must be supervision right from within the health unit to the health sub-district, the district and then the health centre to see that what people were trained in is what actually is being done." (Manager)

Almost all providers felt that the quality of care they could offer was compromised because they were overloaded with work, and managers confirmed some clinics were understaffed. Individual providers take on multiple responsibilities such as antenatal care, labour and delivery, voluntary HIV counselling and testing (VCT) and childhood vaccinations, in addition to family planning services. The work overload was complicated by the tendency of large numbers of clients to visit clinics on open market days and immunisation days.

"We are overloaded. We are small doctors [laughter]. There are clients for VCT there ... in the labour ward; there are two mothers waiting and then there are clients in antenatal clinic... If these mothers wait for so long, they have to go elsewhere and if they do not get their method they will never come back." (Bushenyi, FGD)

Conversely, the multiple responsibilities providers have may be an opportunity to offer more comprehensive - or integrated - reproductive health care.

Providers mentioned the need for training as the 'one thing' that would help improve quality. Nonetheless, providers believed opportunities for additional training for staff members in family planning were rare, but when they did occur the way staff members were chosen to attend offsite training was not transparent. Providers had the impression the same staff members were chosen while others rarely had the opportunity. Managers agreed:

"I think the other barrier is training of certain cadres leaving out others not to benefit from the training, so that you find that it's the same person who has constantly been trained." (Manager)

Managers believed that training was not co-ordinated and was not always relevant because it did not lend itself to the pressing needs of the family planning clinics. They suggested this could be resolved if district and health subdistrict managers could have more control over which provider should be trained.

Providers' responses reflected a lack of knowledge of the latest medical eligibility criteria and practice recommendations. ${ }^{23,24}$ This lack of training and skills limited which methods they offered and limited when clients could receive methods. Providers and managers agreed that many family planning clinics did not stock implants and intrauterine devices because they lacked trained providers who could insert them. Furthermore, lack of training resulted in some providers imposing menstruation barriers - meaning a client must be menstruating before starting a contraceptive method because they were concerned about inadvertently giving a method to a pregnant woman. Managers agreed this practice occurred and admitted this could result in unintended pregnancies.

"To me, some providers believe that once a client is not in her menses they should go back [home without contraceptives]." (Manager)

"[The client] said that "last time I went to the health facility for family planning and they told me to come back when I am in my menses, by the time I went back I was already pregnant!"' (Manager)

\section{Societal factors}

Quality family planning care was also affected by important community and social factors such as male participation, financial constraints, misconceptions and leadership support.

Providers reported that many women secretly used contraceptive methods. A woman who hides use and experiences a side effect is at risk of stopping the method rather than switching to a method that might be detected by her husband, they said. Informed choice loses much of its meaning when the primary use criterion is a method that cannot be detected.

"They come and get services except they may want a method which we don't have. Now this lady is escaping from the husband. Then you tell her go to Jinja and does not get counselled, she will not come back." (Iganga, FGD)

In an effort to hide contraceptive use, clients sometimes administered contraceptives in a manner that could lead to contraceptive failure, providers reported. For instance, some clients unpacked contraceptive pills from their original packs so that they appeared like ordinary pharmaceuticals. Providers feared that by doing so, clients might not comply with the instructions for pill use.

Providers reported being threatened more than once with violence by unsupportive husbands.

"At times there are some men who come and attack me saying that their wives are not producing because I am providing family planning to them. So far two men have attacked $m e$ " [where 'attack' referred to being verbally confronted]. (Iganga, in-depth interview)

Conversely, some men force their partners to seek family planning services and even dictate which methods they use. This observation, and the fact that most clients seek family planning services with their minds set on a particular method, makes informed choice counselling difficult.

Perceptions of clients' ability to pay for services influenced the type of care providers offered. Sometimes providers would not bother to make referrals for contraceptive methods or medical treatment if they believed that financial support was lacking. When referred for services, many a client

“... goes back home and she conceives because she cannot afford the method she wanted". (Mpigi, FGD)

Providers were frustrated with continually being faced with clients' misconceptions, which included associating contraceptives with infertility, loss of manhood (in the case of vasectomy), loss of libido, disability, menstrual blood accumulating in the body, and fibroids, among others. Providers reported that these misconceptions were, in part, propagated by politicians and the media, especially radio campaigns that promulgated negative attitudes about family planning, and were thought by providers to cause many clients to discontinue family planning methods. 
Providers and managers thought the government should intervene to stop the proliferation of false information, but they expressed frustration by the lack of political support for family planning.

"[I] do not think that there is political will. The top leadership of Uganda has never talked about family planning and its benefits." (Manager)

They believed that politicians when armed with accurate information would mobilise communities and resources required for improving quality of family planning services.

\section{Discussion and conclusions}

The findings of this study reveal the many challenges faced by family planning providers to offering quality family planning services ranging from organisational to broader societal factors. While much attention has been aimed at improving the six elements of quality that clients' experience, 25 the findings confirm that structural constraints outside providers' control, in part, are barriers to high-quality family planning services. $17,18,26$ The results highlight opportunities to improve the quality of services, but focusing on those elements of quality that clients experience will not be sufficient without also making changes at the organisational and societal levels. For example, at the organisational level, current training opportunities are inadequate, and when they happen the selection process is opaque and the content is not necessarily relevant. Providers' inadequate training hinders their ability to deal with complicated social situations such as clandestine family planning use.

This study also reveals how the community environment influences quality of care in many ways. Clients choose methods based on their relationships with partners and their ability to pay for certain methods or referrals. Misconceptions about methods and demand for certain methods are widely influenced by what clients hear from their leaders and friends. There is a need to identify strategies that increase the support and participation of male partners. Providers' reports suggest that some men, despite their initial resistance, may respond positively when armed with more information about family planning. Indeed, a recent qualitative study from Uganda confirms that men want to be involved in family planning discussions, but they sometimes lack the knowledge. ${ }^{27}$

Managers did not always agree with providers. This suggests a need to facilitate a greater level of interaction between the managers and providers. Managers are in a position to help providers identify problem areas and work with them to solve problems. For example, managers may be able to work with providers to help identify ways to address provider- and organisational-level barriers.

The present analysis confirms that across the organisation and social levels of the ecological framework the barriers providers face in providing quality family planning services are synergistic. For example, lack of sufficient sterilising equipment (organisational level) increases the amount of time clients have to wait for services or results in providers offering methods that do not require use of that equipment (provider level). Providers' lack of knowledge (organisational level) combined with misinformation at the community level makes it difficult for providers alone to combat misconceptions. Solutions to improve quality of care must address not only what clients experience but should also be targeted at the organisational and societal levels since efforts to overcome a particular constraint are less likely to be successful if this interdependence is not taken into account.
Acknowledgements

The authors thank the study participants and the Ugandan Ministry of Health; Dr Dawn Chin-Quee of Family Health International (FHI) for her contribution to study conception and design; Mr Lwanga and Ms Nauma for data analysis; research assistants Janet, Anthony, Lillian and Xavier; the Regional Centre for Quality of Health Care (RCQHC); and Dr Lucy Honig of Boston University and Dr John Stanback of $\mathrm{FHI}$ for reviewing the manuscript.

\section{Statements on funding and competing interests}

Funding Support for this study was provided by the Special Program of Research, Development and Research Training in Human Reproduction, World Health Organization (WHO) under the terms of Service Agreement \#A15248 and by Family Health International (FHI) with funds from the US Agency for International Development (USAID) Cooperative Agreement \#CCP-A-00-9500022-02. The views expressed in this article do not necessarily reflect those of FHI, RCQHC, WHO or USAID.

Competing interests None declared.

References

1 United Nations. Report of the International Conference on Population and Development, Cairo, 5-13 September 1994. New York, NY: United Nations, 1995.

2 Koenig MA Ahmed S, Hossain MB. The Impact of Quality of Care on Contraceptive Use: Evidence from Longitudinal Data from Rural Bangladesh (FRONTIERS Final Report). Washington, DC: Population Council, 2003.

3 Leon FR, Roca S, Rios A, Zumaran A, Feijoo AR. One-Year Client Impacts of Quality of Care Improvements Achieved in Peru (FRONTIERS Final Report). Washington, DC: Population Council, 2004.

4 RamaRao S, Lacuesta M, Costello M, Pangolibay B, Jones H. The link between quality of care and contraceptive use. Int Fam Plan Perspect 2003; 29: 76-83.

5 Sanogo D, RamaRao S, Jones H, N'diaye P, M'bow B, Diop $\mathrm{CB}$. Improving quality of care and use of contraceptives in Senegal. Afr J Reprod Health 2003; 7: 57-73.

6 Frontiers in Reproductive Health. Services Improve Quality but Fail to Increase FP Continuation (OR Summary 30). Washington, DC: Population Council, 2002.

7 Okullo J, Okello Q. Improving Quality of Care for Family Planning Services in Uganda (Final Report). Kampala, Uganda: Regional Centre for Quality of Health Care, 2003.

8 Blacker J, Opiyo C, Momodou J, Sloggett A, SsekamatteSsebuliba J. Fertility in Kenya and Uganda: a comparative study of trends and determinants. Popul Stud (Camb) 2005; 59: 355-373.

9 Uganda Bureau of Statistics (UBOS) and ORC Macro. Uganda Demographic and Health Survey 2000-2001, Calverton, MD: UBOS and ORC Macro, 2001.

10 Katende C, Gupta N, Bessinger R. Facility-level reproductive health interventions and contraceptive use in Uganda. Int Fam Plan Perspect 2003; 29: 130-137.

11 Ali M, Cleland J. Contraceptive discontinuation in six developing countries: a cause-specific analysis. Int Fam Plan Perspect 1995; 21: 92-97.

12 Kols AJ, Sherman JE. Family planning programs: improving quality. Population Reports. Series J, No. 47. Baltimore, MD: Johns Hopkins University School of Public Health, Population Information Program, 1998.

13 Shelton JD. The provider perspective: human after all. Int Fam Plann Perspect 2001; 27: 152-153, 161.

14 Stanback J, Twum-Baah KA. Why do family planning providers restrict access to services? An examination in Ghana. Int Fam Plann Perspect 2001; 27: 37-41.

15 Stolovitch H, Keeps E. Handbook of Human Performance Technology (2nd edn). San Francisco, CA: JosseyBass/Pfeiffer, 1999.

16 Lande RE. Performance improvement. Population Reports, Series J, No. 52. Baltimore, MD: Johns Hopkins Bloomberg School of Public Health, Population Information Program, 2002.

17 Fonn S, Mtonga AS, Nkoloma HC, Bantebya Kyomuhendo G, daSilva L, Kazilimani E, et al. Health providers' opinions on provider-client relations: results of a multi-country study to test Health Workers for Change. Health Policy Plan 2003; 16(Suppl. 1): 19-23.

18 Khan ME, Patel BC, Gupta RB. The quality of family planning services in Uttar Pradesh from the perspective of service providers. In: Koenig MA, Khan ME (eds), Improving Quality of Care in India's Family Welfare Programme. New York, NY: Population Council, 1999; 238-269.

19 Bongaarts J, Bruce J. The causes of unmet need for contraception and the social content of services. Stud Fam Plann 1995; 26: 57-75. 
20 LeCompte MD, Schensul JJ. Designing and conducting ethnographic research. Ethnographers Tool Kit (Vol. 1). Walnut Creek, CA: Altamira Press, 1998.

21 Sallis JF, Owen N. Ecological models. In: Glanz K, Lewis FM, Rimer BK (eds), Health Behavior and Health Education. Theory, Research, and Practice (2nd edn). San Francisco, CA: Jossey-Bass, Inc., 1997; 403-424.

22 Carey JW, Wenzel PH, Reilly C, Sheridan J, Steinberg JM, Harbison KG. CDC EZ-Text: Software for Collection, Management and Analysis of Semi-structured Qualitative Databases (Version 3.06). Atlanta, GA: Conwal Incorporated for the Centers for Disease Control and Prevention, 1998

23 World Health Organization (WHO). Medical Eligibility Criteria for Contraceptive Use (3rd edn). Geneva, Switzerland: WHO, 2004

24 World Health Organization (WHO). Selected Practice Recommendations for Contraceptive Use (2nd edn). Geneva, Switzerland: WHO, 2004

25 Bruce J. Fundamental elements of quality of care: a simple framework. Stud Fam Plann 1990; 21: 61-91.

26 Ndhlovu L. Quality of Care in Family Planning Service Delivery in Kenya: Clients' and Providers' Perspectives. Nairobi, Kenya: Population Council, Africa Operations Research and Technical Assistance Project, 1995.

27 Kaida A, Kipp W, Hessel P, Konde-Lule J. Male participation in family planning: results from a qualitative study in Mpigi District, Uganda. J Biosoc Sci 2005; 37: 269-286.

\section{BOOK REVIEW}

Preventing Cervical Cancer. What Every Woman Should Know. A Szarewski. St Albans, UK: Altman Publishing, 2007. ISBN: 1-86036042-8. Price: $£ 10.95$. Pages: 159 (paperback)

This slim, friendly-looking volume guides the reader from basic anatomy through abnormal smears to colposcopy assessment and treatment. Along the way it takes in the aetiology of cervical cancer, screening controversies and looks to future prospects for human papillomavirus (HPV) vaccination.

As you would expect, Szarewski has given us thorough, balanced and thoughtful coverage of a difficult area. The text is clear and is supported by excellent illustrations throughout. There are also useful suggestions for further reading and for organisations offering information and support.

The jacket suggests the book would be useful for "... every woman, her partner and her doctor". Although this book is principally aimed at the laywoman, many doctors would indeed learn a lot from it too. It could be read straight through, but the chapters also stand alone, and with a good index it could be used for reference too.

I asked a 21-year-old telesales operator for her opinion, after I had treated her for CIN3. She loved this book, finding it extremely helpful and well written in a relaxed style with usefu diagrams. She wished she had read it before coming to the colposcopy clinic.

If I had one quibble it was on the subject of Trichomonas as a possible incidental finding on smear reports; the text suggests "... it is just possible to catch it from swimming pools or lavatory seats". Whatever the truth of this statement, I do not think it a useful point in a book of this kind!

Overall this is an excellent resource, which I look forward to sharing with my knowledgehungry patients.

Reviewed by Kate Weaver, MBChB, MFFP Staff Grade in Reproductive Health Care and Colposcopist, Edinburgh, UK

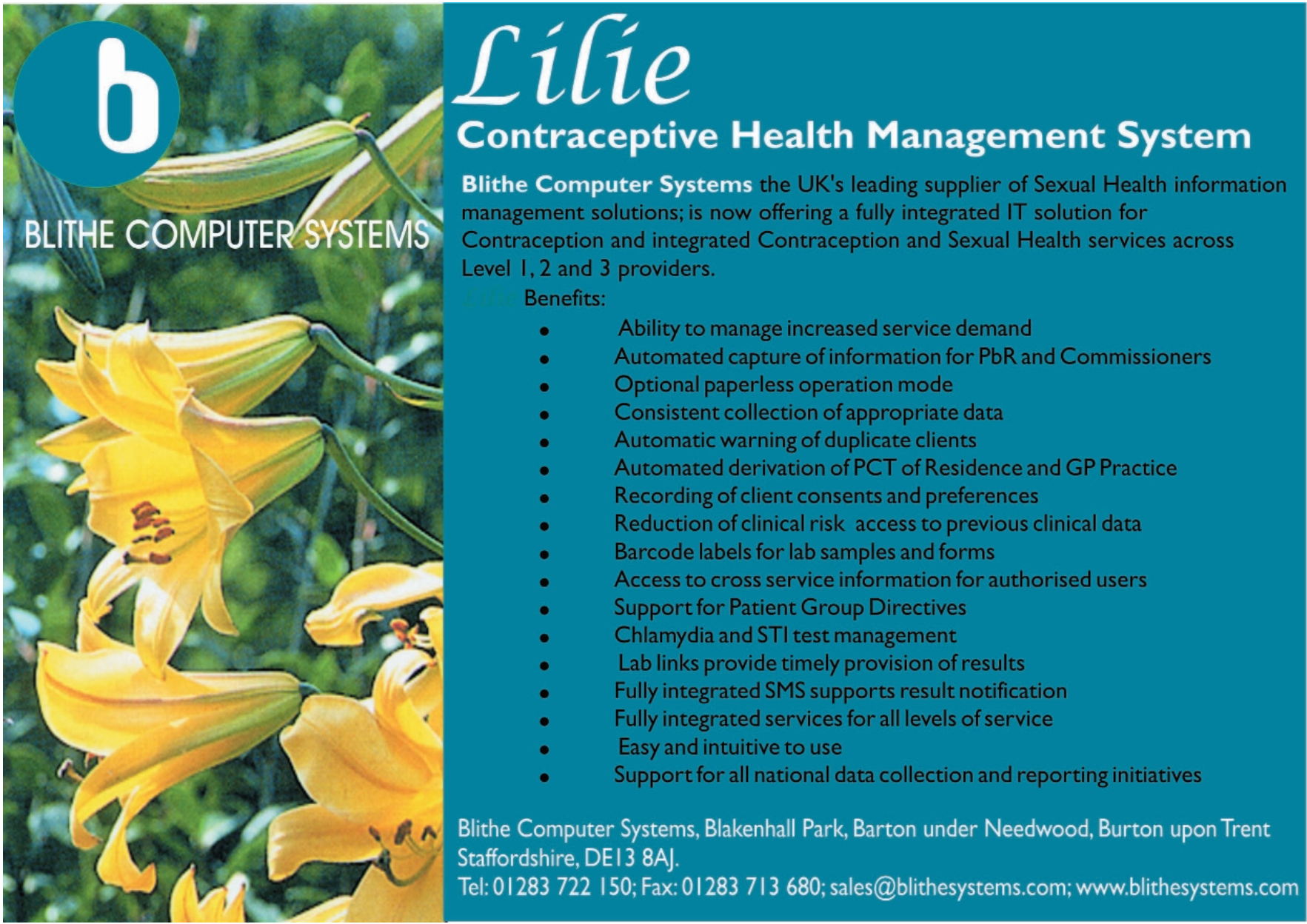

